\title{
Assessment of the Determinants of Urban Household Poverty in North Shewa Zone, Ethiopia: Evidence from Debre Berhan Town
}

\author{
Meseret Endeshaw $^{1} \quad$ Zelalem Adugnaw ${ }^{2}$ \\ 1.Lecturer Department of Economics at Jinka University, Ethiopia \\ 2.Research and Project Data Management officer at Development Bank of Ethiopia
}

\begin{abstract}
Poverty has turned out to be a great global social and economic problem. In Ethiopia, it is multifaceted and deep rooted. The strategies aimed at reducing poverty need to identify and analyze the factors that influence poverty. In this regard, this study was conducted to identify and analyze the extent and determinants of urban poverty in the case of Debre Berhan town. The study made use of cross-sectional household survey data collected from total of 333 randomly selected households in three urban Kebeles of the town. The collected data were analyzed using FGT index and logistic regression. The binary logit model was fitted to identify determinants of poverty. In this case the probability of a household being poor is taken as a dependent variable whiles the set of demographic and socio economic variables were explanatory variables. Using cost of basic needs approach the study found that total poverty line (food and non-food poverty line) of the area using the price deflated national average poverty line is 5,220 birr per year per adult equivalent. Using this poverty line as bench mark the study indicated that 62 percent of sample households are poor. The head count ratio, poverty gap, and severity indices of the survey households were $0.62,0.14$ and 0.30 , respectively. Econometric results of the binary logit regression model revealed that age of household head, education, saving, access to credit, and remittance were found to be as theoretically expected, have negative and significant effect on the probability of a household being poor whereas age square of head of household and dependency ratio alone were found to have positive and significant effect on poverty. Since most of the poor are concentrated around the poverty line as we observe from the poverty gap, policies should focus on absolute poverty rather than relative poverty among the poor. Promoting adult education and saving habit of households, and ensure better access to formal credit through micro credit financing and banks, are indispensable policy interventions to better target urban poverty.
\end{abstract}

Keywords: Urban household poverty, Per Capita Consumption, Determinants, Logistic Regression.

DOI: $10.7176 / \mathrm{JPID} / 50-03$

Publication date:June $30^{\text {th }} 2019$

\section{INTRODUCTION}

Poverty has become a pervasive national and global issue resulting from a state of short-or long-term deprivation and insecurity in basic human needs (Biyase \& Zwane, 2017). Although poverty is relative and more recognized than defined, the poor are those with lower standards of living than a country specific poverty line and people who lack access to the wherewithal to improve their conditions of living themselves unless assisted (Dereje, 2015). It is a complex occurrence that includes different dimensions of deprivation, such as incomes or expenditure of consumption, the insufficiency of goods and services (Mbah et. al., 2016).Available records show that globally, a total of 900 million people are still living below the poverty line based on an income poverty line of $\$ 1.90$ per person per day (World Bank, 2015). Looking beyond the income measure, 1.6 billion people are considered poor across measures of access to social services and security (Bapat \& Bhattacharyay, 2016).

Like inequality, the burden of poverty is unfairly spread among the regions of the developing world, with the largest global share of poor people being in South Asia and the highest intensity in sub-Saharan Africa (Heshmati \& Rashidghalam, 2018). Sub-Saharan African countries (SSA) has the highest poverty rate amongst developing countries, with nearly $60 \%$ of the working population living below USD $\$ 1.90$ per day (Touray, 2016).

The world is urbanizing rapidly, especially in developing countries, where, by 2020, more than half the population is projected to be urban. In sub-Saharan African countries averagely $30 \%$ of the population currently live in urban areas, by 2020 it is predicted that nearly half (46.2\%) of the population will be urban (United Nations, 2013). Ethiopia like many other developing countries has experienced rapid rate of urbanization in the last few years. According to Ethiopian urbanization review (2015), Ethiopian urbanization rate (16\%) is lower than the sub-Saharan average of $30 \%$. However, recently due to high rural-urban migrations and population growth of nearly $3.8 \%$, remarkable urban expansions are observed. If managed proactively, the expansion of urban areas presents a huge opportunity to shift the structure and location of economic activity from rural agriculture to the larger and more diversified urban industrial and service sectors. However, poor management and planning in urban Ethiopia results in the deterioration of urban physical environments and the general living conditions which often do not have access to basic infrastructure and services. Hence, low quality of life, low life expectancy, food shortages and high incidence of poverty characterize most of the urban areas (Teshome \& 
Sharma, 2014).

The multi-dimensional character of poverty in Ethiopia is reflected in many respects, such as destitution of assets, vulnerability and human development. The government has understood the multi-dimensional impacts of poverty and put poverty alleviation and reduction strategy as major socio-economic and political issue in the country. Over the past decade, Ethiopia has achieved positive results in poverty reduction especially in rural areas. However, urban poverty remains a challenge. In response the government of Ethiopia collaboration with donors and non-governmental organizations were developed various social protection strategies. Among these, the Urban Productive Safety Net Programme (UPSNP) was lunched as an alternative intervention, to further alleviate extreme poverty and improve shared prosperity, by enabling poor households to take advantage of the economic opportunities that urban development offers, as well as gain access to equitable social protection services (World Bank, 2015). However, the existence of large number of poor people and the prevalence of economic inequality may bring about social tensions which would induce various criminal acts if situations go beyond the limits of social tolerance. Poverty alleviation would, therefore, enhance economic development and result in improved incomes and better well-being of the people which is a pre-requisite for peace and further development (Mohammed, 2017). Therefore this study is aimed to identifying the factors that affecting urban poverty at household level in the study area in particular and helps to understand the determinant of urban poverty in Ethiopia generally.

\section{Statement of the Problem}

The problem of poverty and how to reduce it remains the most pressing dilemma in the international development debate. It has been an important target of researchers in development literature and various studies point out the level of poverty and its determinants. In understanding the determinants of poverty the economy can consider such determinants in its development plans to alleviate poverty (Heshmati \& Rashidghalam, 2018). Usually Governments and policy makers in developing countries prepare a poverty reduction strategy to guide poverty reduction efforts. However, one of the major weaknesses in most of government's poverty reduction strategy is lack of in-depth information for implementing and monitoring the strategy (Amendah et.al, 2014). Strategies aimed at poverty reduction need to identify factors that are strongly associated with poverty and that are amenable to modification by policy. Therefore, as in many other developing countries even in Ethiopia there is an urgent need to address the issue of poverty and to incorporate poverty reduction policies into development strategies. However, the most important question is: How is the government going to achieve this goal? This question cannot be adequately addressed unless we have information on the level of relative and absolute poverty and characteristics of the poor and how these characteristics determine poverty in the country (Rashidghalam, 2017). Thus it is necessary to document all determinants of poverty and seek ways to alleviate it for the sake of the suffering population.

Prior analysis of poverty in Ethiopia has largely focused on rural rather than urban areas, hence most poverty-related studies have up to now focused on rural poverty rather than urban poverty but the proportion of the poor who live in urban areas is rising fast. In Ethiopia today, large number of poor people live in urban areas because of the continued migration of rural poor in search of better opportunities because of this now a days the urban poverty is the most serious problem (Spieker, 2017). Therefore, the measurement and analysis of urban poverty is crucial for understanding peoples' situations of well-being and factors determining their poverty situations. The outcomes of the analysis are often used to inform policy making as well as in designing appropriate interventions and for assessing effectiveness of on-going policies and strategies. Since the last two decades, as part of the global and national initiatives, the government of Ethiopia together with its development partners has been pushing with a development with aim of achieving a broad based and sustained economic growth.

There is a cultural component and socio-economic difference associated with work habit in earlier study areas; this means that the problem and determinants of urban poverty in different regions and or cultural settings will differ (Melese et.al., 2017). This indicates the need for region specific studies. It is necessary to document all determinants of poverty and seek ways to alleviate it for the sake of the suffering population. There are disparities of the incidence of poverty in urban areas as well as differences from province to province in Ethiopia. Once again the issue of urban poverty may differ from town to town, which calls for studying the situation for each town separately rather than making generalizations based on the studies in few urban centers. Additional gap is the lack of information on the extent and nature of urban poverty in the smaller towns and cities in Ethiopia. As such, it is necessary to study poverty per region (urban area in this research) in order to see the possible differences in causes of this phenomenon and how to eradicate it. Analyzing the socio- economic characteristics of urban areas of the North Shewa zone of Amhara mostly unnoticed by researchers and no detail socio economic study is undertaken previously. This study therefore intends to fill this intellectual gap. 


\section{Objectives of the Study}

The main objective of this study is to assess the determinants of urban household poverty in Ethiopia a case study of Debre Berhan town. Moreover, the study tried to address the following specific objectives:

$>$ To estimate the extent of poverty in the town

$>$ To examine principal factors that determine household poverty in the study area

\section{Hypothesis of the Study}

According to the conceptual framework of the study, there were several factors that influence household's poverty status. So, this paper hypothesized that both demographic composition and socioeconomic characteristics of the household affect household's poverty status. To do so, alternative hypotheses were formulated and tested after the use of statistical analytical techniques, in order to draw conclusions in the research. Individual alternative hypotheses were tested for each area examined in the thesis; this is to say, areas dealing with demographic and socioeconomic factors. The alternative hypothesis was that there was statistical significant relationship between the explanatory variables and households poverty status $(\beta \neq 0)$. The hypotheses were tested after regression analysis of the model. This enabled generalizations from relatively small groups of individuals to other individuals (the population) with similar characteristics. The alternative hypotheses tested in this research were as follows:

* There is an inverse relationship between age of the household head and household poverty status.

* Female-headed households are likely to be poorer than their male counterparts.

* There is a significant negative relationship between the education of the Household head and the poverty status of a Household head.

* Employment status of household head affects household poverty status negatively.

* Households with larger dependency ratio are more prone to poverty.

* Households with access to credit service are less likely to face poverty compared to those with less access.

The hypotheses were separated so that each category of variables could be examined. The statistical hypotheses for all the research hypotheses are that there is no difference in the population variances, which is tested by chi-square statistic at 95 percent of confidence interval. The results of the above processes are discussed in chapters four with summary of the conclusions and recommendations, being given in chapter five.

\section{LITERATURE REVIEW}

The issue of poverty has been an important target of researchers in development literature and various studies point out the level of poverty and its determinants. As a result, several empirical studies have been carried out on the subject. This section presents a succinct summary of empirical studies related to factors affecting urban poverty.

Alex (2014) analysed and reviewed the causes of poverty in Africa. The study found that poverty in Africa is caused by a number of factors including corruption and poor governance, limited employment opportunities, poor infrastructure, poor resource usage, wars and unending conflicts, poor World Bank and IMF policies, among others. Poverty the study revealed is also caused by cultural and structural factors. The poor lacks the capacity to influence social processes, public policy, and resources allocation. Poor people are also said to lack access to relevant skills and knowledge, education and personal development that could improve their livelihoods. The study concluded that poverty can only be fought in the presence of strong institutions, and equitable distribution of resources. This requires a non-corrupt government. However, in Africa, programmes designed to fight poverty are not fully implemented because the funds end up in the hands of corrupt individuals, who pocket the majority.

Spaho (2014) identified the determinants of poverty in Albania, at the household level using a questionnaire. The data were collected during November 2013, and direct interviews were conducted with 215 households living in rural and urban area. Two regression models were estimated based on the collected data, a log-linear model with the logarithm of per capita monthly consumption as the dependent variable and a logistic model with poverty status as the dependent variable, and a set of economic and demographic variables as the explanatory variables. He found that the variables that impacted the per capita consumption of the household and the poverty status of the household were household size and residence. Poverty alleviation efforts should be made to improve the social and demographic characteristics of the households, since the number of the poor is increased in both urban and rural areas. To reduce poverty, great attention must be paid to the manufacturing sector, agriculture and tourism.

Oruc (2015) analyzed the effect of mass forced displacement on urban poverty in Bosnia and Herzegovina. He started with a discussion of the specific features of the process of forced displacement and their possibly different effect on urban poverty compared to voluntary migration, based on qualitative evidence collected through interviews with people who experienced forced displacement during the conflict in the 1990s. Then, the 
probit model of determinants of poverty, based on the Living Standards Measurement Survey data, was estimated in order to provide empirical evidence of the effect of mass forced displacement on urban poverty, as well as the difference in the poverty incidence among displaced people compared to voluntary migrants. The study found that consumption is significantly lower among displaced households, while incidence of poverty is not affected by displacement status. The evidence also contributes to the migration literature by providing specific results about the relationship between mass forced displacement and urban poverty.

Ngunyi et.al (2015) examined the multidimensional aspects of poverty in one Kenya's culturally diverse region of the Lake Victoria basin household census data and binary logistic regression model. They also investigated statistical models based on factors that characterize the demographic characteristic of individuals, in determining the predictors of poverty for better policy formulation. They found that poverty measures do overlap to capture a percentage of the sample as poor. The analysis shows that education, gender (being male), marital status, assets (livestock, water sources, and wall materials) and age of the head of the family have statistically positive effects on the likelihood of an individual falling into poverty.

Farah (2015) identified the factors that have relative effect on poverty of the households on Bangladesh using principal component analysis to create an asset index which gave the Social Economic Status (SES) of each household. Finally, he was estimated a logistic regression based on this data with the SES (that is poor and non-poor) as the dependent variable and a set of demographic variables as the explanatory variables. The results presented in his paper suggested that the DHS data can be used to determine the correlates of poverty. The results also suggested that demographic and household data can describe poverty. The probability of a household being poor depends on the ownership of assets and other household data.

Meyer (2016) presented an analysis of the predictors of poverty of low-income communities in the Northern Free State region, South Africa. Predictors, such as gender of head of household, type of dwelling, property ownership, housing subsidy, quality of service delivery, income and employment, were analyzed to determine their impact on poverty in the study region with a specific focus on Zamdela, Kwakwatsi and Tumahole. A total of 2678 households were included in the survey. He aggregated income of households to determine the status and level of poverty. A logistic regression was utilized to determine the impact of the various predictors of poverty. Of all these, the most significant for a household were found to be the gender of the head of the household and employment status. Strategies for poverty alleviation should be focused on local problems by means of local research. The implementation of appropriate policy and projects is also important for success.

Bapat and Bhattacharyay (2016) analyzed the determinants of Financial Inclusion of Urban Poor in India using a multiple regression model using socio-economic characteristics of the households. He pointed out that urban financial inclusion needs urgent attention with rapidly increasing urbanization, unique requirements of urban population and increasing poor and low income population living in urban areas, particularly slum areas. Access to financial services to all citizens, particularly to low income and poor people are a key to promote inclusive growth. Finally the paper suggests appropriate policies and strategies for enhancing financial inclusion in urban areas through building low cost personalized distribution network, creating asset linked and collateral free credit schemes, leveraging Aadhar (biometric identity card) platform, creating targeted product and service offering, strengthening business correspondent cells, and setting up urban financial inclusion centers.

Gachanja and Kinyanjui (2016) examined Household Poverty Determinants in Kenya using both the binary and ordered logistic models. The paper shows that the Demographic and Health Survey Wealth Index need to be used with caution in the analysis of household poverty in Kenya. Thus, they depict a case of varied results when the wealth index is directly used with regional comparison, and discover that in both the binary and ordered logistic models, the years of education of household head, their marital status, the size of a given household and the region of residence (province) strongly determine household welfare status. They also observe that these characteristics are even more important in explaining household probability to poorest, and thus, lay emphasis on results obtained while controlling for household region of residence (province) to those that distinguish between rural and urban households.

Melese et. al., (2017) analyzed the factors that influence poverty and the extent and determinants of urban poverty in the case of Nekemte town. The study used both primary and secondary data; where the primary data were collected from total of 203 randomly selected households in six urban Kebeles of the town. They applied logit model to identify determinants of poverty. They also take the probability of a household being poor is a dependent variable and the set of demographic and socioeconomic variables were explanatory variables. The study was employed basic needs approach to identify households as poor and non-poor. Based on this and using the price deflated national average poverty line of birr 5,220 out of the 203 surveyed households, 42 per cent were found to be poor. The head count ratio, poverty gap, and severity indices of the survey households were $0.42,0.032$ and 0.01 , respectively. The logit estimation result revealed that family size and rural-urban migration have positive and significant effect on the probability of a household being poor. The study found that sex of the household head, education level, and salary employment were found to have negative and significant effect on poverty. Promoting female education should be an important element of poverty reduction policies this is 
because education and fertility are negatively correlated such a policy could also have an impact on household size which is another important determinant of poverty in Nekemte.

Mohammed (2017) measured urban poverty and identified the determinants via employing logistic regression. He used survey data collected by Southern nations, nationalities and peoples' region (SNNPR) bureau of finance and economic development (BoFED) in collaboration with Arba Minch University for 5,015 urban households. Urban food poverty measured using incidence, gap and severity indexes. The use of logistic regression to identify the determinants of urban poverty end up with marital status, family size, total dependency, education level, saving habit, and source of energy were found to be statistically significant variables. Finally, he recommended that pre and post marriage orientations to reduce divorce and input support for windowed, limiting family size and in turn dependency using short and long term solutions, and supplying social and physical infrastructure such as education, financial institutions and power are viable options to reduce urban poverty in the region.

Heshmati and Rashidghalam (2018) examined the extent of poverty in different provinces and districts in Rwanda using both consumption and income per capita. They look at the determinants of household poverty and focuses on four categories for studying the determinants of poverty in the country. The income based study of poverty and the consumption based poverty analysis is based on 7498 observations from 2012 database. They found that older household heads and female-headed households are more likely to be poor. Also living in rural and semi-urban areas increases the probability of being poor. Asset ownership decreases the probability of being poor. Finally the findings of the study serve as evidence for policymakers to employ poverty alleviation policies. Increasing investments in physical infrastructure, creating jobs for female-headed households and improving educational levels of household heads should also be focused on.

\section{Conceptual Framework}

Based on different recent literatures, it is possible to identify factors that affect the likelihood of an individual or household experiencing poverty. As pointed out in the literature, poverty can result from either individual/household; that is, households characteristics or due to structural barriers that are out of an individual's or households' control. These characteristics can be divided into two broad categories of socioeconomic and demographic factors. Hence, based on insights from literatures, and to show an easy of interaction among variables of interest, conceptually the model of interaction between explanatory variables and urban poverty can be constructed in the frame work below.

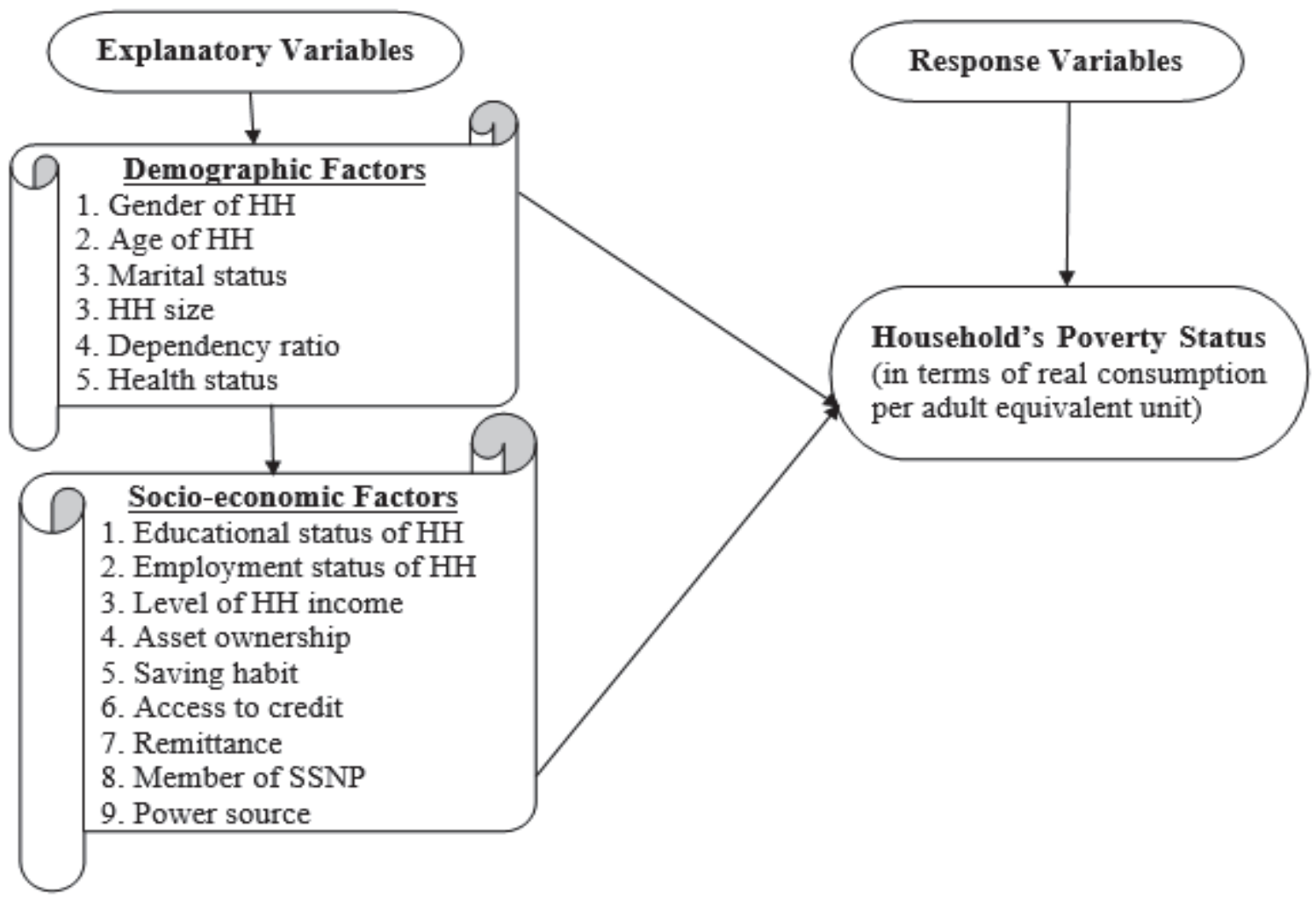

Figure 2.1: Diagrammatic representation of conceptual framework.

The conceptual framework in Figure 2.1 above, illustrates the interaction of key variables involved and how they are interrelated. 


\section{METHODS AND MATERIALS OF THE STUDY}

\section{Description of the Study Area}

This study was conducted in Debre Berhan town during June, 2018. The town is a capital of North Shoa Zone of Amhara national regional state, Ethiopia, which situated 130 kilometers to the North East of Addis Ababa which is located latitude and longitude of $9041^{\prime} \mathrm{N} 39032^{\prime} \mathrm{E} / 9.6830 \mathrm{~N} 39.5330 \mathrm{E}$ and with an avg. elevation of 2,840 meters and receives an annual rainfall of $920 \mathrm{~mm}$ while the temperature varies from 2.4 co in November to 23.3 co in June. The town has an estimated area of 14.71 square kilometers which gives Debre Birhan a density of $4571 \%$ per square kilometer. The town has a total of nine Kebeles. A Kebele is the lowest administrative unit in Ethiopia. According to Central Statistical Agency of 2016/17 Debre Birhan town has estimated total population reached that of 103,450 total populations, and 10,367 households of whom 4,888 are men and 5, 479 are women. Table 3.1: Number of total household in Debre Birhan town (2016/17)

\begin{tabular}{|l|l|l|l|}
\hline \multirow{2}{*}{ Name of Kebeles } & \multicolumn{2}{|c|}{ Sex of household } & \multirow{2}{*}{ Total number of household } \\
\cline { 2 - 4 } & Male & Female & \\
\hline Kebele 01 & 432 & 457 & 889 \\
\hline Kebele 02 & 710 & 812 & 1522 \\
\hline Kebele 03 & 360 & 415 & 775 \\
\hline Kebele 04 & 732 & 844 & 1576 \\
\hline Kebele 05 & 348 & 370 & 718 \\
\hline Kebele 06 & 702 & 805 & 1507 \\
\hline Kebele 07 & 247 & 260 & 507 \\
\hline Kebele 08 & 650 & 760 & 1410 \\
\hline Kebele 09 & 709 & 758 & 1465 \\
\hline Total household & 4890 & 5479 & 10369 \\
\hline
\end{tabular}

Source: Central Statistical Agency (CSA, 2017)

Figure 3.1: Map of the Study area

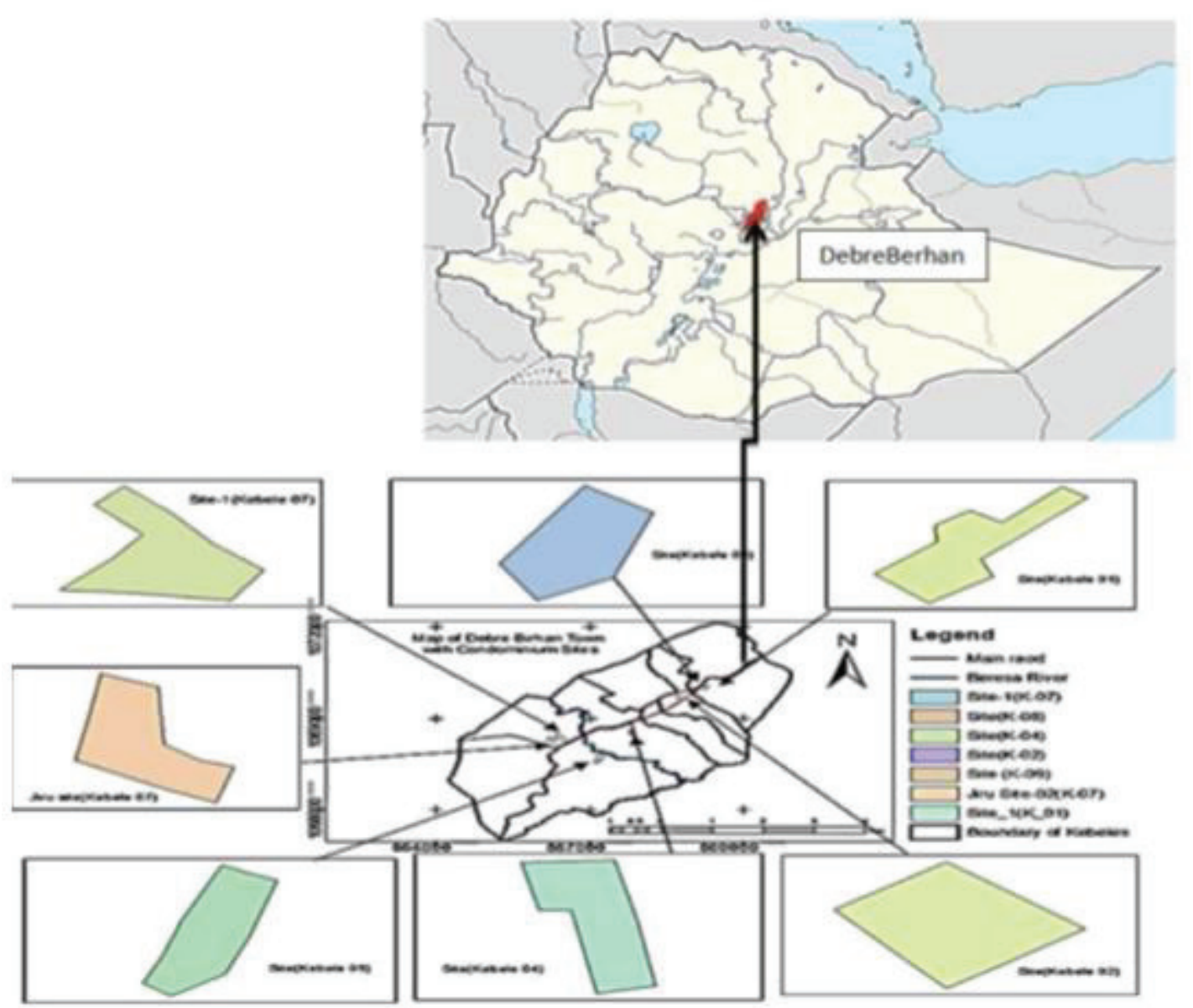

Source: Central Statistical Agency (CSA, 2017) 


\section{Sampling Techniques and Sample Size determination}

The target populations of the study were the number of households who reside in the town at the time of the survey. Two stage sampling procedure was used in the selection of representative sample in the study area during the reference period. The first step involved purposive selection of three Kebeles out of the total number of nine Kebeles in the town through making discussion with and by taking information from Debre Berhan town municipality. These Kebeles were selected mainly because they were the most slum-dwellers in the town. Finally, from purposively selected Kebeles, numbers of Households were selected randomly using simple random sampling technique so as to each household has an equal chance to be selected and who were ultimately interviewed. Households were taken as the primary sampling unites. The required sample size was determined from a finite population, based on mathematical formula developed by Yemane (1967) at 95\% confidence level, degree of variability $=0.5$ and level of precision at $5 \%$. The numbers of respondents to be interviewed in the study were determined as follows:

$$
\mathrm{n}=\frac{\mathrm{N}}{1+\mathrm{N}\left(\mathrm{e}^{2}\right)}------------------------
$$

Where: $\mathrm{n}=$ sample size to be determined

$$
\begin{aligned}
\mathrm{N} & =\text { entire population of interest } \\
\mathrm{e} & =\text { error margin }(0.05)
\end{aligned}
$$

By substituting the values in the formula we have: $\mathrm{n}=\frac{2000}{1+2000(0.05)^{2}}=333$; Thus, the sample size for the study is 333 .

Therefore, 333 sample urban household heads out of 2000 total households were drawn by simple random sampling method and sample size in each Kebeles was determined based on proportion to size of the households. Table 3.2: Summary of sample frame and sample size

\begin{tabular}{lcc}
\hline Kebeles & Number of households & Sample taken \\
\hline Kebele 03 & 775 & 129 \\
Kebele 05 & 718 & 120 \\
Kebele 07 & 507 & 84 \\
\hline Total & $\mathbf{2 0 0 0}$ & $\mathbf{3 3 3}$ \\
\hline
\end{tabular}

Sources and Methods of Data Collection

To achieve the stated objectives, both primary and secondary data were used. To obtain the primary data required for this study, cross sectional survey data was collected from selected households in the study area through structured questionnaire on March and April 2018. Before the data was collected, the questionnaire was pre-tested on selected households to evaluate the appropriateness of the design, clarity, and relevance of the questions. The appropriate modification was made on the pre-tested questionnaire in order capture the relevant information related to the study objectives. The data was collected at household level through enumerator's observation, measurement and interviews. The survey was planned in such a way that it could help to get a complete information on the respondents demographic, social and economic characteristics. The questionnaires were prepared on the way of information about the determinants of urban household poverty at household level and then four enumerators those who are familiar with the culture and language of the community were recruited and trained on the content of the questionnaire and interviewing process. Besides, personal observation, informal focus group discussion with respondents was employed to generate primary information. Information pertaining to urban households and their family's demographic and socio-economic characteristics like gender age, and average monthly income were obtained directly through questionnaire i.e. (open and closed ended questionnaires), was designed for this purpose. A cross sectional primary data was supplemented by collecting secondary data from relevant sources. Secondary data was gathered from published and unpublished documents from government offices and other relevant organizations like CSA, NGO so as to produce extra information on the characteristics of urban household poverty. Primary data were collected through the administration of structured questionnaire by a team of five trained enumerators to 333 households from selected Kebeles in the town. Finally, the sample of data collected from the field were organized, coded, and entered in to STATA software package version 12 to process the data.

\section{Methods of Data Analysis}

This section presents different approaches that have been used to analyze data in line with study objectives. Data were analyzed using FGT index estimation and binary logistic regression analysis. Poverty index estimation, using cost of basic need approach of per adult equivalent consumption expenditure method was employed to classify the respondents into poor and non-poor households in a bid to establishing the poverty status of the individual households. Then, the FGT index or $\mathrm{P}_{\mathrm{a}}$-alpha measures has been decomposed to draw profiles of multidimensional poverty. Under Econometric analyses, binary logistical regression model was permitted to 
identify the probable determinants of urban poverty at household level in the study area. Lastly, diagnostic tests of the model were investigated.

\section{Method of Determining Poverty Line}

Poverty line is the starting point of every point of analysis, below which a household was classified as being poor and above which a household was classified as being non-poor. Income or consumption is traditionally used to measures material deprivation (Busisa, 2011). According to Jonathan and Shahidur (2009) especially consumption rather than income is viewed as the preferred welfare indicator because consumption better captures the long-run welfare level than current income. Consumption may better reflect households' ability to meet basic needs. Income is only one of the elements that allow consumption. Consumption reflects the ability of household's access to credit and saving at times when their income is very low. Hence, consumption reflects the actual standard of living (welfare). In most developing countries, income report of households is likely to be understated compared to consumption expenditure report (MoFED, 2012). Income is so erratic and seasonal that it may be very difficult for respondents to recall. Hence, many of the income poverty measures (such as the head count ratio, poverty gap ratio, and the squared poverty gap ratio) use consumption rather than income in the conduct of poverty analysis (Mohammed, 2017). This is the reason why consumption as an indicator of welfare and cost of basic need approach $(\mathrm{CBN})$ using per adult equivalence to fix poverty line is used in this paper.

Consumption to be an indicator of household's welfare, it has to be adjusted for difference in the calorie requirement of different household members (for age and gender of adult members). This adjustment could be made by dividing real household consumption expenditure by an adult equivalent scale that depends on the nutritional requirement of each family member. The adult equivalent scale must therefore be different for different age groups and the gender of adult members. Besides, household consumption may have to be adjusted for differences in prices across regions and for different point of time to take care of the difference in the cost of basic needs across space and over time.

Total poverty here refers to an aggregate measure of poverty that takes into account both the food and nonfood requirements. Here it is worth noting how poverty lines are established. The most widely used method of estimating poverty line is the cost of basic needs method because the indicators will be more representative and the threshold will be consistent with real expenditure across time, space and groups. According to this approach, first the food poverty line is defined by choosing a bundle of food typically consumed by the poor. The quantity of the bundle of food is determined in such a way that the bundle supplies the predetermined level of minimum caloric requirement (2200 kilocalorie). This bundle is valued at local prices or at national average prices to get a consistent poverty line across regions and groups due to the diversification of consumer choice in all countries, the international poverty line is not useful to estimate poverty within a nation. Thus countries develop their individual national poverty lines (Khan et.al., 2015). Then a specific allowance for the non-food goods consistent with the spending of the poor is added to the food poverty line. To account for the non-food expenditure, the food poverty line is divided by the food share of the poorest quartile or quintile. To do so groups of consumption items that generate 2200 kilo calories are valued at 2011/12 national average prices is determined to be Birr 3781. This poverty line was adjusted against price deflated for the year 2011 and it becomes 5,220 birr total poverty line per adult person per year consumption expenditures (Melese et.al, 2017). The households having consumption expenditure level per capita is under the national poverty line that is needed to fulfill his/her basic need for food and non-food goods were considered poor in the current analysis. This minimal level of consumption is differently called as the 'poverty line' and is a margin which represent the breaking point among poor and non-poor. This is called the absolute margin of poverty. In the regression analysis, it is denoted by 1 if the respondent is poor; otherwise 0 if the respondent is non poor at the time of the survey. In this view, the outcome of urban poverty was been measured as dichotomous variables. Algebraically, this can be expressed as:

$$
\mathrm{HPS}=\mathrm{PL}_{\mathrm{i}}: \quad\left\{\begin{array}{l}
<5,220 \text { birr } \rightarrow \text { poor } \\
\geq 5,220 \text { birr } \rightarrow \text { nonpoor }
\end{array}\right.
$$

Where: HPSi refers to poverty status of the $i^{\text {th }}$ household, and PLi represents the poverty line for $i^{\text {th }}$ household, $\mathrm{i}=1,2,3 \ldots 333$.

\section{Measuring the Extent of Poverty}

After constructing poverty line using cost of basic need approach (CBA), the poverty situation of households was analyzed using the FGT Index which is commonly applied for poverty analysis The three most widely used poverty indices: the head count index (P0), the aggregate poverty gap or poverty gap index (P1) and poverty severity index (P2) was employed. The head count index measures the share of the population whose consumption is below the poverty line (the share of the population that cannot afford to buy a basic basket of 
goods). The poverty gap index measures the extent of the poor (living below the poverty line) how far away from the poverty line and the poverty severity index measures not only the gap but also the inequality among the poor (a higher weight is placed on those households further away from the poverty line).

More precisely, these measures can be defined in terms of the well-known Foster, Greer, and Thorbecke (1984) $P_{\text {a }}$ class of poverty measures. When real per-adult (per capita) household expenditure, $Y$, is ranked as

$\mathrm{Y} 1 \leq \mathrm{Y} 2 \ldots . \mathrm{Yq} \leq \mathrm{Z}<q+1 \ldots \ldots . . \mathrm{Y} n,------------------(3.1)$ The mathematical expression of the FGT index is specified as follows:

$\mathrm{P} \alpha(\mathrm{Z}, \mathrm{Y})=\frac{1}{\mathrm{~N}} \sum_{1}^{\mathrm{q}}\left[\frac{\mathrm{Z}-\mathrm{Yi}}{\mathrm{Z}}\right]^{\alpha}, \mathrm{a} \geq 0$, for $\mathrm{Y}<\mathrm{Z}--------------$

Where: $P \alpha$ is a measure of poverty, Zis the poverty line (in terms of consumption expenditure), $N$ is total population, $q$ is total number of poor households normally those below the poverty threshold, and $Y$ is the total consumption expenditure. The poverty index, $P \alpha$ changes when $\alpha$ takes different values. For instance, when $\alpha$ is 0,1 , and $2, P \alpha$ equals the head count index $(P 0)$, the poverty gap index $(P 1)$, and the poverty severity measure $(P 2)$, respectively. In this study, the FGT indices of poverty are used as comparative poverty measures to the MPI.

\section{Econometric Model Specification}

To estimate the significant factors that determine household's poverty status, empirical model was utilized. Choosing an appropriate model and analytical technique depends on the type of variable under consideration (Geberehiwot, 2008). Here, the dependent variable of interest (household's poverty status) is binary that takes a value of 1 and 0 . An essential shortcoming of classical linear regression model is that it only considers numerical (continuous) data for dependent variable. But, many interesting variables are categorical in practice. Following this, a regression analysis in which the dependent variable involves qualitative responses (i.e., 'yes' or 'no' type) was usually done using discrete choice models (Ermias, 2018). For the purpose of this study, the dependent variable $\mathrm{y}$ is defined to indicate whether a household is poor or not. In this case, we can let $\mathrm{y}=1$ denote a household is poor and $\mathrm{y}=0$, otherwise.

Wooldridge (2002) mentioned three approaches to develop probability model for a binary response dependent variable. These include Linear Probability Model (LPM), Logit Model and the Probit or Normit Model. In this study, Logit model was used since it has several advantages over other methods. One of the merits of this model compared to other methods is that the independent variables can take on any form since logistic regression makes no assumptions about the distribution of the independent variables (Cox, 2004). Unlike ordinary least square regression, logistic regression does not require normally distributed variables, does not assume homoscedasticity, the parameter estimates under logit model are fully efficient and generally it has relatively flexible data requirements. The logistic regression model has become one of the most widely used statistical tools in the analysis of binary outcome data arising from either prospective studies or case-control studies (Shu \& Wenqing, 2017).

The LPM is plagued by several problems, such as non-normality of error term, heteroscedasticity of error term, the fitted probabilities can be less than zero or greater than one but probability cannot be so, and generally the lower R2 values (Gujarati, 2004). Nonetheless, the logit and probit models are quite similar in many applications except that the logit model involves cumulative logistic function and probit model follows the normal cumulative distribution function. Though there is no exciting reason to choose one over the other, due to comparative computational simplicity, the logit model was used in this study to investigate the key explanatory factors that may influence the urban households' poverty status. Following Gujarati (2004), the functional form of cumulative logit model is specified as follows:

$\mathrm{Pi}=\mathrm{E}(\mathrm{y}=1 / \mathrm{Xi})=\frac{1}{1+\mathrm{e}^{-\left(\mathrm{x}^{\prime} \beta\right)}}------------------13.3$

For ease of exposition we can re-write the above function as;

$$
\begin{aligned}
\mathrm{Pi}=\mathrm{E}(\mathrm{y}=1 / \mathrm{Xi}) & =\frac{1}{1+\mathrm{e}^{\mathrm{Zi}}} \\
& =\frac{\mathrm{e}^{\mathrm{z}}}{1+\mathrm{e}^{-\mathrm{z}}}------------------
\end{aligned}
$$

Where: $Z i=X^{\prime} \beta=\beta 0+\beta 1 X 1+\beta 2 X 2+\cdots+\beta n X n, \beta 0$ is an intercept, $\beta 1, \beta 2$ and $\beta$ n are slope coefficients and $\mathrm{X} 1, \mathrm{X} 2$, and $\mathrm{Xn}$ are related household characteristics.

Eqn. (3.4) represents (cumulative) logistic distribution function. Under this case, the probability, $\mathrm{P}_{\mathrm{i}}$ ranges between 0 and 1 , as $Z_{i}$ ranges from $-\infty$ to $+\infty$. One problem of LPM resolved, but now we have created another problem, that is, $P_{i}$ is non-linearly related to $Z_{i}$ (or explanatory variables) and also to the parameters ( $\beta$ 's). So the 
model is non-linear and thus we cannot use the OLS procedure to estimate the parameters. However, the problem of non-linearity may be resolved through log transformation as follows:

If $P i$ is the probability of household being poor, is given by eqn. (3.4), then (1-Pi), the probability of household being non poor can be expressed as:

$1-\mathrm{Pi}=\frac{1}{1+\mathrm{e}^{\mathrm{zi}}}----------------------------$

Therefore, we can write

$\frac{P i}{1-P i}=\frac{1+\mathrm{e}^{\mathrm{zi}}}{1+\mathrm{e}^{-\mathrm{zi}}}=\mathrm{e}^{\mathrm{zi}}-$

Eqn. (3.6), the ratio of Pi to 1-Piis termed as the odds ratio in favor of household being poor. It is simply the ratio of the probability that a household is likely to be poor to the probability that it will be non-poor. Now if we take the natural logarithm of equation (3.6), we obtain the following equation:

$L i=\ln \left[\frac{\mathrm{Pi}}{1-\mathrm{Pi}}\right]=\mathrm{Zi}=\beta 1 \mathrm{X} 1+\beta 2 \mathrm{X} 2+\cdots+\beta \mathrm{nXn}-------------(3.7)$

That is $L i$, is the natural logarithm of the odds ratio, is not only linear in the explanatory variables $\mathrm{Xi}$, but also in the parameters from the estimation point of view. $L$ is also called the logit, and hence the name logit is given for models like in eqn. (3.7) above.

Now for estimation purpose, by introducing the disturbance term $\varepsilon$ i, the logit model can be written as follows:

$L i=\ln \left[\frac{\mathrm{Pi}}{1-\mathrm{Pi}}\right]=\mathrm{Zi}=\beta 1 \mathrm{X} 1+\beta 2 \mathrm{X} 2+\cdots+\beta \mathrm{iXi}+\varepsilon \mathrm{i}------------$

It is easy to see that the log-odds ratio is: $\ln L=Z i=X^{\prime}$. Accordingly, the coefficient $\beta$ measures the change in log-odds ratio for a unit change in a covariate. By inspecting the sign of independent variable's coefficient of estimate, the influence of that variable on the probability of a household being poor can be determined. However, the parameter estimates of the logit model provide only the direction of the effect of independent variables on the dependent variable. As such, these estimates represent neither the actual magnitude of change nor the probabilities. Differentiating eqn. (3.8) with respect to the covariates provides the marginal effects of the characteristics on the probabilities and specified as follows:

$\partial P i$

$\frac{\partial P i}{\partial X i}=P i(1-P i) \beta i------------------------$ (3.9)
Therefore, eqn. (3.9) represents the marginal effects of the logit model. Hence, the maximum likelihood estimation method was applied in this study. For dummy independent variable, the relevant change occurs from 0 to 1 and thus the partial derivative does not make any sense. In this case we calculate the predicted probability to see the effect of dummy independent variable on the probability of an event to happen (dependent variable). A technique called variance inflation factor (VIF) was used to measure the degree of linear relationships among the quantitative explanatory variables. VIF shows how the variance of an estimator is inflated by the presence of Multicollinearity. Multicollinearity has been checked before running the model using variance inflation factor (VIF) and contingency coefficients (C). VIF shows how the variance of an estimator is inflated by the presence of Multicollinearity (Gujarati, 2004). Each selected continuous variable is regressed on the other, so that the coefficient of determination $\left(\mathrm{R}^{2}\right)$ would be constructed. According to the Rule of Thumb, a variable is said to be highly collinear, if R2 exceeds 0.9 or VIF exceeds 10 (Gujarati, 1995). VIF is expressed as:

$\operatorname{VIF}(\mathrm{Xi})=\frac{1}{1-\mathrm{R}^{2}}----------------------(3.10)$

Where: $\mathrm{R}^{2}=$ the adjusted square of the multiple correlation coefficients

$\mathrm{Xi}=$ the explanatory variable $(\mathrm{Xi})$

Moreover, contingency coefficients were computed for each pair of qualitative variables to check for the degree of association among the qualitative variables. The contingency coefficients were computed as follows.

$C=\sqrt{\frac{X^{2}}{N+X^{2}}}-------------------------$

Where: $\mathrm{C}$ is the contingency coefficient, $X^{2}$ is Chi-square and $\mathrm{N}$ is the total sample size. The values of $\mathrm{C}$ range between 0 and 1, zero indicating no association between the variables and values close to 1 indicating a high degree of association, which means high degree of Multicollinearity (Dereje \& Haymanot, 2018). 
Table 3.3: Description of Explanatory Variables used in the Binary Logit Model and their Expected Signs

\begin{tabular}{|c|c|c|c|}
\hline Variable & Type & Description & $\begin{array}{l}\text { Expected } \\
\text { sign }\end{array}$ \\
\hline SEX & Dummy & $\begin{array}{l}\text { Is a dummy variable taking value } 1 \text { if the household head is } \\
\text { male, } 0 \text { otherwise }\end{array}$ & - \\
\hline AGE & Continuous & Age of the household head in years & $=$ \\
\hline AGESQ & Continuous & Age square of the household head in years & + \\
\hline EDUCTN & Continuous & $\begin{array}{l}\text { Formal education of household head (number of years in } \\
\text { school). }\end{array}$ & = \\
\hline EMPLY & Dummy & 1 if household has access to employment, 0 otherwise & \\
\hline EXPERI & Continuous & It indicates year of households head job experience & \\
\hline MARTIALST & Dummy & $\begin{array}{l}\text { Marital status of the household head ( } 1 \text { if married, } 0 \text { if } \\
\text { otherwise) }\end{array}$ & $+/-$ \\
\hline FAMLSZ & Continuous & Total number of members in the household & + \\
\hline DEPRAT & Continuous & Dependent household members measured in number & \\
\hline INCOM & Continuous & Average household income per month (Birr) & $=$ \\
\hline CREDIT & Dummy & 1 if household got credit, 0 otherwise & \\
\hline SAVING & Dummy & $\begin{array}{l}\text { It indicates whether households has habit to saving in } \\
\text { financial institutions ( } 1 \text { savers, } 0 \text { otherwise) }\end{array}$ & - \\
\hline REMITT & Dummy & Households has access to constant remittances (Yes, No) & \\
\hline YEAR & Continuous & $\begin{array}{l}\text { Year of residence in the town it indicates how long } \\
\text { household head has lived in the town }\end{array}$ & - \\
\hline SOCIAL & Dummy & $\begin{array}{l}\text { Households membership in social organization like edir } \\
\text { and equib, dummy variable ( } 1 \text { if yes; } 0 \text {, otherwise) }\end{array}$ & - \\
\hline UPSNP & Dummy & $\begin{array}{l}\text { It takes value } 1 \text {, if a household is beneficiary of safety net } \\
\text { program, } 0 \text { if not involving in it. }\end{array}$ & - \\
\hline HEALTH & Dummy & Health status of household head $(1=$ non-ill, $0=$ ill $)$ & \\
\hline POWER & Dummy & $\begin{array}{l}\text { Indicates households has access to power source ( } 1 \text { if } \\
\text { electricity used for cooking and lighting, } 0 \text { otherwise) }\end{array}$ & $=$ \\
\hline ASSET & Continuous & Total value of fixed assets owned by household head (birr) & \\
\hline
\end{tabular}

\section{Explanation of Variables and Their Hypothesis}

Following the adoption of literatures, the explanatory variables included in our logistic regression analysis and their hypothesized effects on household's poverty status are discussed below.

\section{Dependent Variable}

The dependent variable for this study is household poverty, which is dichotomous. The information to categorize households into two groups was obtained by comparing the total consumption expenditure per adult equivalent per annum to the poverty line. This poverty line was computed based on the national poverty line using 2011 consumer price index (CPI) of birr 5,220 per adult person per year. The households having consumption expenses needed for food and non-food items of the lowest income quartile under birr 5,220 were considered poor in the current analysis.

$$
\text { POVHH }_{i}=\left\{\begin{array}{l}
1, Y_{i}<Z \text { (poor) } \\
0, Y_{i} \geq Z \text { (non poor) }
\end{array}\right.
$$

Where: POVHHi $=$ household poverty status of the $i^{\text {th }}$ household. $Y i=$ consumption expenditure of households. $\mathrm{Z}=$ poverty line.

\section{Predictor Variables}

The dependant variable is hypothesized to be a function of the following explanatory variables. The selection of the explanatory variables was guided by the conceptual framework discussed in methodology section taking in to account poverty profiles used in previous empirical works in Ethiopia and developing countries. These are variables that are expected to either positively or negatively influence the household's poverty status in the study area. The followings are selected explanatory variables included in the model as described above.

Sex of the Household Head: Household head is a person who economically supports or manages a household or 
for reason of age is considered as head by other members of the household. It is a dummy variable taking a value of 1 for male headed households and 0 otherwise. According to Rogan (2016), Female-headed households are increasingly worse off than male-headed households. Because, households headed by male have more access to employment opportunities and more secured from vulnerability and poverty than female headed ones (Shete, 2010; and Sharma, 2014). It was hypothesized that male headed households are less likely to be poor than female headed ones.

Age and Age Square of Household Head: It is a continuous variable measured by number of years. As age of household head increases, there is greater tendency to acquire knowledge and experience (Busisa, 2011). Thus, it is hypothesized that age and poverty are negatively correlated. Use the age squared of the household head as an explanatory variable in order to capture any possibilities of lifecycle effects and non-linearity in the relationship between household's age and living standards. In contrary, the age squared variable intends to capture the negative effect on consumption is may be due to a decrease in labor supply to the household and a poor decision capacity of the head with an increment in age (Spaho, 2014).

Education of Household head: It is believed to be a necessary condition to equip individuals with the knowledge of how to make a living. Education is a necessary factor for stimulating a country's economic growth as it allows people to be more productive and provides more opportunities for its citizens (Muhammedhussen, 2015; and Jakiel, 2016). This is a continuous variable measured by level of formal education attainment. It is a variable that refers to the number of years spent in schools or its equivalent as a measure of educational attainment of the household head and it is expected to affect the welfare of the household positively (World Bank Group, 2017).

Marital status of Household head: Marital status of the household head has economic implication on household's income level. Some literatures recommend that single headed households have high probability to escape from poverty than married. The assumption is that households headed by married individuals are supposed to be larger in family size. Large families in developed countries mean large labor force which in turn reduces the incidence of poverty. But in developing countries the reverse in most cases holds true in that larger households are associated with high incidence of poverty because many of the labor force are unemployed (Melese et.al., 2017). Although this question had four options for the participants (Never Married, Married, Divorced, Widowed), a number were grouped for ease of analysis and interpretation. The dummy variable was used to denote this variable is 1 , for married or living together and 0 , otherwise.

Household Size: Household size is a continuous variable and refers to the total number of Household members who live in the same home during the survey period. It represents the total number of a household size is adjusted to the standard adult equivalent unit. Some studies found that household size as being positively related with poverty by assuming that family size increases, obviously the probability of having economically non active members or children and doddering ages is higher, then household resource per head decreases. As result the cost of living regarding education, health and other social activities increase (Dawit, 2011; Sharma, 2014; Muhammed Hussen, 2015). Whereas other studies see an inverse association in expectation that the larger households have a larger labor force that contributes to the household's source of income (Minot \& Baulch, 2005).However, in the present study, it is hypothesized that households with larger size have more probability of being falling into the poor category than those with lesser family size in developing country.

Dependency Ratio: As a continuous variable, it is the ratio between economically inactive (age less than 15 and above 65) with active labor force (age between 15 and 65) with in a household. When a large family size corresponds with the availability of adequate adult labor, it can have a positive effect. A household with high economically non active members shows high dependency ratio and it is more likely to be poor (Ermias, 2018). Therefore, it is hypothesized that dependency ratio and poverty are positively associated.

Remittance: Income from families working elsewhere is an important determining factor of household's consumption. Remittances from other sources of finances are an important dummy explanatory variable for whether or not the household receives remittances that can be gauged as one of the indicators of measuring poverty. The values of remittance received are critically important in supporting inclusive growth and reducing poverty through boosting household consumption (UNDP, 2015; Berisso, 2016). Remittance is done as part of their indigenous culture of helping each other. It can be considered as an extra source of income, it is likely to improve household welfare. It is expected that having relative economic support from abroad and other areas within the country has positive impact in reducing the poverty status of households. It is hypothesized that getting financial support from migrant family members living elsewhere is likely and negatively be related to the poverty status of the household.

Year of Residence in the Town: A fresh migrant from the rural areas is classifiable as a rural household and it has been argued that residence is a determinant of poverty such that residents of rural areas are more likely to be poor than urban ones. It is expected that the longer one has been living in an urban area the less likely will they be poor (Tacoli et.al, 2015). We have investigated this in terms of how long one has lived in the town and hypothesized that there is a significant correlation with poverty incidence. 
Saving: Households with practice of saving and credit utilization have better chance to escape from poverty because they have good ground to invest on profitable businesses and coping short term market shocks (Melese et.al., 2017).

Access to Credit: Access to credit is a dummy variable with a value 1 if the households received credit, either from formal or informal sources and 0, otherwise. Those households who received the credit wanted to have better possibility to spend on activities they want. They can improve production and productivity by adopting different business activities. Access to credit is expected to have a positive influence as it enables to solve short term liquidity constraints (Dereje \& Haymanot, 2018). Credit can also be used as a consumption smoothing mechanism in the event of cash shortage in the household. It is therefore hypothesized that households with credit access will have less chance of being poor than their counter parts.

Membership in Social Relation: This is an aspect of social capital a household access by being a member of various community organizations like networks, social relations, and associations. It is a dummy variable which is proxied by 'Equb' and assigned value 1 for households who participates in 'Equb'; and 0 otherwise.

Productive Safety Nets Participation: This is one of the government's food security programs that targets on the most affected groups of the society. It is a dummy variable taking the value 1, if the household receives food aid 0 otherwise. Despite the huge amount of aid received through Productive Safety Net Program, its impact as development resource is inconclusive in both theoretical and empirical evidences (Calfa, 2010). Food aid can increase resources for current consumption; increase and improve the nutritional status of the poor. Thus, by directly alleviating hunger and poverty, food aid is hypothesized to serves as a wage for the poor. It might have either positive or negative relationship with households' poverty status depending of the adequacy of the program.

Real Asset value (RAV): we were evaluating in Ethiopian birr the total household assets, to determine their level of income variation among households. Households those who have better asset value may have a less vulnerable to poverty than those who have less assets. Therefore, real asset value was assumed to have a negative relationship with poverty. According to Alex (2014), the lack of accumulation of assets in the form of property contributes to poverty. Jakiel (2016) supported the notion that asset accumulation leads to poverty alleviation. A house or property functions as a shelter and as collateral for borrowing and could be used as a venue for income generation business operations (Calfa, 2010).

Household Head Income Level: The amount of household income at any one time shows the extent of poverty; or household's economic status. Economic theory tells that a household with a relatively better income will lead a decent life; and hence, reduces the incidence of poverty. Increased levels of income, largely provided through employment opportunities, have a significant effect on the reduction of poverty (Mok and Sanyal, 2007). This indicated that households become poor if they lose their source of income, especially through job losses.

Power Source: Urban households especially students and females collect fire wood for lighting and cooking purpose. The situation will have an impact on effectiveness of students and environmental sustainability in addition to lose of economic time that reduces productivity (Rashidghalam, 2017)

Household Health Status: Households with members that frequently get sick are hypothetically exposed to poverty. Lack of proper health services will make people to become weak and unproductive (Hagenaars, 1986). Households with frequent patient members take a value of 1 , and 0 otherwise.

\section{RESULTS AND DISCUSSION}

\section{Analysis of Extents and Dimensions of Poverty}

This section discusses the level of poverty and its dynamics based on the FGT poverty measure. The FGT indices namely head count ratio, short-fall/poverty gap and severity of poverty are used to show how much the magnitude of poverty looks like in the study area. The estimated poverty line was used to estimate poverty indices in the study area using the FGT class of poverty measures developed by Foster et. al. (1984) are used to explain the extent of poverty in the study area. Accordingly, 0.62, 0.14, and 0.30 are the computed head count index, poverty gap and poverty severity, respectively (Table 4.3).

Table 4.3: Poverty indices of sample households

\begin{tabular}{l|l}
\hline Poverty index & Index value \\
\hline Poverty head count index $(P 0)$ & 0.62 \\
Poverty gap/depth index $(P 1)$ & 0.14 \\
Poverty severity index $(P 2)$ & 0.30 \\
Annual Total poverty gap(TPG) & $533,934.85$ \\
Average poverty gap(APG) & $2,579.40$ \\
\hline
\end{tabular}

Source: Own computation from survey data (2018)

The most widely used poverty indices are the percentage of the poor (headcount index), the aggregate poverty gap (poverty gap index), and the distribution of income among the poor (poverty severity index). The 
poverty measure itself is a statistical function that translates the comparison of the indicator of household wellbeing and the chosen poverty line into one aggregate number for the population as a whole or a population subgroup.

As already discussed above the poverty measure (P0) developed by Foster, Greer and Thorbecke (1984) are used to explain the extent of poverty in the study area. This index tells us the proportion of population, whose income or consumption expenditure falls below the predetermined poverty line. It is the share of the population who cannot afford to buy or consume basic basket of goods. The resulting poverty estimates for the study area (Table 4.3) shows that the percentage of poor people measured in absolute head count index $(\alpha=0)$ is about $62 \%$. This figure indicates that this proportion of the sampled households in Debre Berhan town live below absolute poverty line. This implies that $62 \%$ of the population are unable to get the minimum calorie required (2200 kcal per day per adult) adjusted for the requirement of non-food items expenditure. Putting differently, these proportions of sample households are unable to fulfill the minimum amount of income i.e., Birr 5220.00 per adult equivalent per year and live under absolute poverty.

The poverty gap/depth index measure captures the mean aggregate income or consumption shortfall relative to the poverty line across the whole population. It gives information about the households on how far they are from the poverty line. This index measures the extent to which households on average fall under the poverty line. This index does not indicate the inequality changes among the poor. It is computed by adding all the shortfalls of the poor, and dividing the total by the total resource needed to bring all the poor to the level of the poverty line. For the poor, poverty gap equals poverty line less actual income or consumption and for the non-poor above the poverty line it is considered to be zero.

Thus, the poverty gap can be used as a measure of the minimum amount of resource necessary to eradicate poverty. In the case of Debre Berhan town, poverty gap index shows the amount that should be transferred to the poor with right targeting to bring all the poor out of poverty. That is, each poor should get exactly their income or expenditure shortfalls (the amount he/she needs) to be lifted out of poverty. The depth of poverty gap of Debre Berhan town is 0.14 as shown in Tables 4.3. This implies that the amount of resources required to get people out of poverty in the town is $14 \%$ of consumption spending per adult equivalent. When the poverty gap index becomes higher, the amount of resources required to spend to the poor under proper targeting becomes higher. When we see the annual short fall of the poor's consumption expenditure, it is on average 2,579.40 birr. This implies that on average birr 2,579.40 per annual were required to bring a poor person in the town just to the poverty line. The analyses of outputs in the respective Kebeles administration provide the same information as explained above for the whole of Debre Berhan Town.

Severity of poverty measure reflects the sum of two components, an amount due to the poverty gap, and an amount due to inequality amongst the poor. That means the index undertakes both the distance separating the poor from the poverty line and the inequality among the poor. The value of this index is higher for households far away from the poverty line. The FGT severity index (the squared poverty gap, $\alpha=2$ ) in the consumption expenditure reveals a 30\% fall below the threshold line implying severe inequality. It indicates the share of individuals whose incomes were below the absolute poverty line was 30 per cent. In other words, it means that there is a high degree of inequality among the lowest quartile population.

\section{Results of the Econometric Model}

An essential part of any regression analysis involves the diagnostics checking before fitting the model. As such, the likely existence of multi co-linearity among the explanatory variables was checked by computing the Variance Inflating Factor (VIF) and Contingency coefficients (C). From the result as indicated in the appendix, the regression diagnostics result of VIF for each of the continuous explanatory variables was found to be significantly less than the standard cut off value of 10 and revealed the none-existence serious multi co-linearity problem among the continuous variables included in the model. The diagnostics check results of $\mathrm{C}$ also shown very lower values than the standard value of 0.75 and hence confirmed that there was no serious problem of colinearity among discrete independent variables included in the model. As a result, all twenty variables were fitted in the logistic regression model. After fitting the model, the post-estimation diagnostics checks were undertaken to evaluate the overall model. A logistic model is said to provide a better fit to the data if it demonstrates an improvement over the intercept-only model (also called the null model, which has no predictors). Consequently, such an improvement is usually examined by the Likelihood Ratio (LR) test. It tests the null model which tells us that none of the explanatory variables are linearly related to the log odds of the dependent variable i.e., poverty status in this case.

\section{Empirical Analysis of the Determinants of Urban Household Poverty}

Although the results of the descriptive analysis provide a useful insight into the characteristics of the household's poverty status in the town, for ultimate conclusions about the relationship between explanatory variables and poverty situation, a binary logistic regression analysis needs to be conducted. As a result this section explored 
Logistic regression analysis in order to examine the correlates of poverty. Table 4.3 below is the result from output of logistic regression model which presents the signs, magnitudes, and statistical significance of the estimated parameters and how much the observed values were correctly predicted by the logistic regression model. In the logistic regression output of this study, the Hosmer and Lemshow goodness of fit test shows that the model is good fitted with chi-square 11.07 and with the significance level of 0.1979 which is a value greater than 0.05 and indicating support for the model. The LINK test result in the appendices also confirms the fact that the model is adequate. Evidence of a GOOD FIT is reflected in a non-significant HATSQ here the p-value for _HATSQ is 0.734 . This suggests good evidence of overall goodness-of-fit is reflected in a non-significant pvalue. The other evidence of GOOD FIT is reflected in an ROC curve that lies above the 45 degree line reference area under the ROC curve $=0.9077$ says that $90.77 \%$ of the observations are correctly classified (see appendices). In addition, goodness of fit in logistic regression analysis is measured by count R2 which indicates the number of sample observations correctly predicted by the model. The count R2 is interpreted based on the principle that if the predicted probability of the event is less than 0.50 , the event will not occur, and if it is greater than 0.50 , the event will occur (Maddala, 1981). Hence, the model results showed that the logistic regression model correctly predicted $84.98 \%$ of sample households. It is apparent from the results that the fitted model correctly predicted $84.98 \%$ of the observed values. The sensitivity (the number of households correctly predicted by the model as poor) was $79.75 \%$, while the specificity (the number of households correctly predicted by the model as non-poor) was $90 \%$. Therefore, the model predicted both groups accurately.

Table 4.4: Maximum likelihood estimates of the binary logit model.

\begin{tabular}{l|l|l|l|l}
\hline \multicolumn{1}{c|}{ Explanatory Variables } & \multicolumn{1}{c|}{ Coefficient $(\boldsymbol{\beta})$} & \multicolumn{1}{c|}{ Standard Error } & $\mathbf{Z}$ & \multicolumn{1}{|c}{$\mathbf{P}>|\mathbf{Z}|$} \\
\hline Sex of head of household & .0177409 & .0203978 & 0.87 & 0.385 \\
Household head age & -.0121021 & .0039609 & -3.06 & $0.002^{* * *}$ \\
Household head age square & .0000983 & .000036 & 2.73 & $0.007 * * *$ \\
Education level & -.0048379 & .0017825 & -2.71 & $0.007 * * *$ \\
Employment Status & .000332 & .0247393 & 0.01 & 0.989 \\
Job experience & -.0008702 & .0009358 & -0.93 & 0.353 \\
Work hour per day & -.0027441 & .0031008 & -0.88 & 0.377 \\
Year of residence & .0003236 & .0009516 & 0.34 & 0.734 \\
Marital Status & -.0080608 & .0211731 & -0.38 & 0.704 \\
Family size & -.0101829 & .010586 & -0.96 & 0.337 \\
Dependency ratio & .037885 & .0114833 & 3.30 & $0.001 * * *$ \\
Estimated asset value & -.0029741 & .0065788 & -0.45 & 0.652 \\
Level of Income & $1.11 \mathrm{e}-06$ & $2.59 \mathrm{e}-06$ & 0.43 & 0.668 \\
Saving Habit & -.5782054 & .0323819 & -17.86 & $0.000^{* * *}$ \\
Accesses to credit & -.1339515 & .0253295 & -5.29 & $0.000^{* * *}$ \\
Remittance & -.0834403 & .0215928 & -3.86 & $0.000^{* * *}$ \\
Safety net program & -.0029085 & .0184734 & -0.16 & 0.875 \\
Social relation & -.0155776 & .0207689 & -0.75 & 0.454 \\
Power source & -.0078548 & .0216316 & -0.36 & 0.717 \\
Health status & .0309432 & .0256537 & 1.21 & 0.229 \\
Constant & 1.296316 & .1141512 & 11.36 & 0.000 \\
\hline
\end{tabular}

Number of observation $=333$

LR chi2 $(20)=213.70$

Prob $>$ chi $2=0.0000$

Pseudo R2 $=0.4631$

Log likelihood $=-123.8926$

Sensitivity_Correctly Predicted Poor households $=79.75 \%$

Specificity_Correctly Predicted non-poor households $=90 \%$

Correctly Classified Based on Predicted $\operatorname{Pr}(\mathrm{D})>=0.5$ Cut Value $=84.98 \%$

Note: $* * *$ denotes level of significance at $1 \%$.

Source: Stata output computed from Field survey Data, July 2018

\section{Discussion on Significant Explanatory Variables}

The logistic regression model shows that from the total of twenty explanatory variables hypothesized to influence household's poverty status seven of them; namely age of household head and its square, year of schooling that head of households attend, Dependency ratio, Saving habit of households, accesses to credit, and Remittance were statistically significant at less than $1 \%$ probability level. The coefficients of threaten variables were not statistically significant at the conventional probability levels implying that they were less important in 
explaining the variability in households poverty status in the town. These variables are sex of household head, employment status of the household head, family size, year of residence, job experience, average work hour per day, estimated asset value, level of income, participation in community institutions (proxied by membership in 'Equb'), participation in productive safety net programs, power source and head of household health status. Thus in what follows, the estimation result of the binary logit model and its interpretations of the significant explanatory variables will be discussed.

Age of the household and its square: The age of a household head was negatively and significantly affected poverty status of households at $1 \%$ probability level showing an inverse relationship with household poverty. This means for every unit increase in household's age, the odd ratio is in favor of household's poverty status decreased by a factor of 0.021 , keeping other variables constant. The finding was constant with Busisa (2011) who demonstrated that age of household head has negative relation with household poverty status. The policy implication is that higher aged household heads there is greater tendency to acquire knowledge and experiences as well as they are more likely to be engaged in multidimensional livelihood strategies. In doing so, they relatively have better exits from poverty than young aged household heads. However, age squared of the household head is positively and significantly related to the probability of being a poor household at 1 percent level of significance. This may be due to a decrease in labor supply to the household and a poor decision capacity of the head with an increment in age and it is lined with the findings of Spaho (2014).

Education level of household head (year of education): The coefficient on education reflects the prime role that human capital plays in determining poverty. In fact, education is an important dimension of poverty itself, when poverty is broadly defined to include shortage of capabilities and knowledge deprivation. It has important effects on the poor children's chance to escape from poverty in their adult age and plays a catalytic role for those who are most likely to be poor. This variable affects poverty situation negatively and significantly at less than $1 \%$ probability level. The negative relationship indicates that households have higher year of schooling are less probability of being poor than that of households lower year of schooling. Therefore, it deserves an important place in formulating poverty reduction strategies. The possible explanation is that household head education largely contributed on working efficiency, competency, diversify income, adopting technologies and becoming visionary in creating conducive environment to educate dependants with long term target to ensure better living condition than illiterate ones. This is due to educated household head plays a significant role in shaping household members. Thus, being literate reduces the chance of becoming poor in the sample households. The maximum likelihood estimates of the binary logit model of the variable reveal that year of schooling increased by one year/grade/ the probability of being poor decreased by $0.48 \%$. The finding of this study was found consistent with what had been found by Ayalneh et. al. (2005), Tsegaye et. al. (2014), and Melese et. al, (2017).

Dependency Ratio: This variable is found to be significant at less than $1 \%$ level of significance in determining the household poverty. The result shows that the variable is found to have positive impact on the probability of being poor in the study area. In other words, the probability that a household will be poor increases as the household size increases due to an increase in the number of dependents. The coefficient of logistic regression 0.37 implies that, ceteris paribus, the probability of being poor increases by $3.78 \%$ as dependent adult equivalent increases by one. The possible explanation can be that those households with many dependent family members could be poor because of high dependency burden. This shows that those households with large economically non-active members tend to be poorer than those with small family size. Result is in conformity with earlier empirical studies by Abu (2013) and Farah (2015) whose findings showed that a larger dependant household is associated with greater incidence of poverty.

Saving Habit: Results of logistic regression in this study revealed that the coefficient of saving is found to be negative and significant at 1 percent precision level and implies that being a saver reduces the probability of falling in to poverty by 57 percent compared to non-savers keeping other factors constant. Households with practice of saving and credit utilization have better chance to escape from poverty because they have good ground to invest on profitable businesses and coping short term market shocks.

Accesses to credit: The sign of the coefficient of access to credit shows a negative relationship with poverty and is significant at $1 \%$ probability level. The negative relationship implies that households with access to credit service have more chance to be non-poor than households without access to credit. The result is fully in conformity with the prior expectation. This is due to the fact that credit gives the household an opportunity to be involved in income generating activities so that derived revenue increases and purchasing power of the household to escape from risk of probability of being poor advances. Moreover, it helps to smooth consumption when household face with temporary food problem. Holding other variables remain constant, the odds ratio in favor of a probability of being poor decreases by 0.13 as household's access to credit increases by one unit. The findings coincide with similar study conducted by Mohammed (2017) who reported that credit can be used to invest in various income generating activities.

Remittance: The logistic regression result provides strong eviedence that the level of poverty tends to be lower in households with accesse to flow of remitance.It is statistically significant at $1 \%$ precision level. If the head of 
household has access to remittance, the probability of this household falling in to poverty reduces by $8.3 \%$ compared to remittance non receiver households keeping other factors constant. This may be because of the increases the household's income of the poor by the virtue of the remittance and/or the money remitted might be channeled to more productive activities, indicating the powerful role of remittance to maintain a sustainable reduction in poverty.

However, the result of logistic regression indicated that some government policy related variables such as productive urban safety net programs, family size, employment status of the household head, participation in community institutions which was proxied by membership in 'Equb' and edir, job experience, power source, and head of household health status, all had no effect on the probability of a household being poor. The coefficients were statistically insignificant (Table 4.4). Besides, some policy variables are not only insignificant but also these expected signs are contrary to what the researcher expected, they are in way far away from other empirical findings. The researcher believes that in a certain circumstances, the empirical analysis has to be supported by the qualitative analysis so that the possible reasons for statistical insignificance might be captured and future researchers might consider this gap.

\section{CONCLUSION AND RECOMMENDATIONS}

It has been observed that the dimensions and causes of poverty are vast and complex. Poverty affects people of different characteristics in different ways, because they play different roles, have different needs and face different constraints and opportunities. It is most likely that communities or households in extreme poverty differ from the average and non-poor communities/households in several distinct ways such as in accessibility of social services, demographic characteristics, and other socioeconomic conditions. Proper understanding of these characteristics and conditions constitutes an essential starting point and is a key to the formulation of policies, designing appropriate strategies and practical steps that the government can take in order to reduce poverty and promote sustainable growth at macro and micro levels.

One of the second gross and transformation plane (GTP-II) goals is reduction of poverty and hunger. Currently, poverty situation is global agenda. The results and analyses of the study also suggest that policy interventions are necessary to reduce poverty in the town. Poverty can be addressed through different ways. Thus, this research has tried to explore the covariates of urban poverty using a sample of 333 representative households taken from the urban Kebeles of the town. Based on our empirical findings, we draw the following policy implications that should be considered/given proper attention during policy formulation, planning and implementation processes to tackle poverty.

First, since most of the poor are concentrated around the poverty line as we observe from the poverty gap, policies should focus on absolute poverty rather than relative poverty among the poor. Second, it is important to facilitate improved educational levels of household heads so that they can provide their families with better jobs and sources of income. Since, educational attainment of the head of the household is found to be the most important factor associated with urban poverty clergy clearly suggests ways of focusing on the value of education adequate education in addressing incidence of poverty. Specifically, Promoting higher education may also have important contribution to minimize poverty in the town. Based on the logit model output, educational level directly varies with the level of household welfare. Thus, it is recommended that both formal and informal educations which broaden thinking capacity of the poor should be flourished. Adult education should be given attention. Households with unemployed heads are more vulnerable to poverty from descriptive analysis; new development projects should primarily consider the employment and income generating opportunities of those sections of the society with less paying jobs. Therefore, training programs for the unemployed could be established in to improve their employability.

The estimation of the model for determinants of poverty shows that larger dependency ratio significantly increase the probability of the household to be poor. As a result number of dependants cause households to be poorer. Hence, there is need to provide employment opportunities for household members through the government with the support of the private sector. This will lead to lower dependence ratio which tends to decrease poverty in the region. Because poverty decreases with increase in educational level, policy actions that tend to increase educational and training opportunities for the poor should be encouraged and formulated since reducing poverty in the long run is not likely to achieve much success without adequate investment in education.

The expansion of financial institutions, awareness creation, incentives should guide financial institutions' activity in order to increase the number of savers and amount of saving. Similarly, most poor households did not have access to credit which has great potential to assist them to graduate from poverty. It is recommended that credit delivery mechanism should continue targeting the poor which helps them to purchase food and non-food items of goods and the provision should be accompanied by continuous follow up and technical support. Besides households with remittance source of income are better endowed with better and additional income thus, government should encourage remittance from abroad for nations of the country.

Lastly, this study has attempted to come up with the result of the analysis with defined scope however a lot 
remained to be unanswered. Future research is needed to yield more results on poverty predictors in urban Ethiopia and to determine where poor communities have actually been lifted out of the poverty trap. To provide basic information on the patterns and determinants of urban poverty, the social, political and environmental dimensions, descriptive data on purchasing patterns of poor households, specific characteristics that make urban poor more vulnerable to poverty and their coping mechanisms demands future researchers' attention. The study exploits one time survey and no one be able to address the kind of poverty prevalence in the area. Additional household survey becomes crucial to make a consistent welfare assessment.

\section{RIFERENCE}

Abu, G. M. (2013). The Challenges and Policies of Poverty Reduction in Ethiopia. Ethiopian E-Jornal for Research and Inovative Foresight, 5 (1), 94-117.

Alex, A.-K. (2014). Causes of Poverty in Africa: A Review of Literature. American International Journal of Social Science, 3 (1), 147-154.

Amendah, D. D., Buigut, S., \& Mohamed, S. (2014). Coping Strategies among Urban Poor: Evidence from Nairobi, Kenya. journal pone, 9 (1), 1-8.

Ayalneh, B., Konard, H., \& Korf, B. (2005). Determinants of Poverty in Rural Ethiopia. Quarterly Journal of International Agriculture, 101-120.

Bapat, D., \& Bhattacharyay, B. N. (2016). Determinants of Financial Inclusion of Urban Poor in India: An Empirical Analysis. Munich: Center for Economic Studies and Ifo Institute.

Berisso, O. (2016). Determinants of Consumption Expenditure and. In A. Heshmati, Poverty and Well-Being in East Africa, Economic Studies in Inequality, Social Exclusion and Well-Being, Switzerland (pp. 139-164). Springer International Publishing.

Biyase, M., \& Zwane, T. (2017). An Empirical Analysis of the Determinants of poverty and household welfare in South Africa. Munich Personal RePEc Archive (MPRA) , 1-19.

Busisa, E. (2011). DETERMINANTS OF POVERTY AMONG HOUSEHOLDS IN UGANDA. MAKERERE: MAKERERE UNIVERSITY.

Calfa, M. (2010). Food Aid and Rural Poverty in Ethiopia: Empirical Evidence from Rural Households in Ethiopia,Discussion Paper. Antwerpen, Belgium: Institute of Development Policy and Management.

Cox, N. J. (2004). Speaking Stata: Graphing model diagnostics. The Stata Journal , 449-475.

Dawit, A. (2011). Extent and Determinants of Household Poverty in Rural Ethiopia: A Study of Six Villages. East Afr. Soc. Sci. Res. Rev, 21-49.

Dereje, F. D. (2015). Cooperatives as Pathways to Socioeconomic Empowerment: Critical Review. International Journal of Academic Research, 2 (5), 1-9.

Dereje, H., \& Haymanot, A. (2018). Poverty and income inequality in Girar Jarso District of Oromia Regional State, Ethiopia. Journal of Development and Agricultural Economics, 10 (1), 1-14.

Ermias, G. G. (2018). An Empirical Examination of the Determinants of Food Insecurity among Rural Farm Households: Evidence from Kindo Didaye District of Southern Ethiopia. Business and Economics Journal, $9(1), 1-12$.

Farah, N. (2015). "Impact of Household and Demographic Characteristics on Poverty in Bangladesh: A Logistic Regression Analysis". Eastern Illinois University: 2015 Awards for Excellence in Student Research and Creative Activity , 1-21.

Foster, J., Greer, J., \& Thorbecke, E. (1984). A Class of Decomposable Poverty Measures. Econometrica, 57, 817.

Gachanja, P. M., \& Kinyanjui, G. K. (2016). Household Poverty Determinants in Kenya: A Demographic and Health Survey Wealth Index Approach. The Journal of Pan African Studies, 9 (3), 52-66.

Geberehiwot, T. (2008). Rural Food Security in Tigrai, Ethiopia.Policy Impact Evaluation. A thesis submitted to the International Institute for Geo-information Science and Earth observation in partial fulfillment of the requirements for the degree of Master of Science in Geo-inf. The Netherlands.

Greer, J., \& Thorbecke, E. (1986). “A Methodology for Measuring Food Poverty Applied to Kenya”. Journal of Development Economics, 59-74.

Gujarati, D. (2004). Basic Econometrics. Fourth Edition. The McGraw-Hill companies.

Hagenaars, A. (1986). The Perception of Poverty. Center for Research in Public Economics, Leyden University. Netherlands: Elsevier Science Publishers.

Heshmati, A., \& Rashidghalam, M. (2018). Measurement and Analysis of Poverty in Rwanda. East Africa Collaborative PhD Program. Jönköping, Sweden: Jönköping International Business School (JIBS).

Jakiel, L. (2016). Disparities of Poverty in Eastern Africa: Ethiopia and Kenya. Glob. Majority E-J, 7 (1), 4-17.

Mbah, S. I., Mgbemena, G. C., \& Ejike, D. C. (2016). Urban Poverty Incidence in Nigeria: A Study of Awka Metropolis Anambra State,Nigeria. International Journal of Business and Social Science, 7 (5), 173-185.

Melese, T. C., Solomon, K. M., \& Amsalu, B. (2017). Determinants of Urban Poverty: The Case of Nekemte 
Town, Eastern Wollega Zone of Oromia Regional State. Journal of Poverty, Investment and Development, 32.

Meyer, D. F. (2016). PREDICTORS OF POVERTY: A COMPARATIVE ANALYSIS OF LOW INCOME COMMUNITIES IN THE NORTHERN FREE STATE REGION, SOUTH AFRICA. INTERNATIONAL JOURNAL OF SOCIAL SCIENCES AND HUMANITY STUDIES, 8, 132-150.

Minot, N., \& Baulch, B. (2005). Poverty mapping with aggregate census data. Review of Development Economics, 9 (1), 5-24.

MoFED. (2012). Ethiopia's Progress towards Eradicating Poverty .

Mohammed, B. M. (2017). Measurement and Determinants of Urban Poverty in Case of Southern Nations, Nationalities, and Peoples' Region (SNNPR), Ethiopia. International Journal of Scientific and Research Publications, 7 (3), 181-190.

Mok, T., Y, G., \& Sanyal., C. (2007). . The determinants of urban household poverty in Malaysia. Journal of Social Sciences, 3 (4), 190-196.

Muhammed hussen, M. (2015). Determinants of Rural Income Poverty in Ethiopia: Case Study of Villages in Dodola District. Glob. J. Manage. Bus. Res. B Econ. Commer, 15 (11), 24-32.

Ngunyi, A., Mwita, P. N., \& Odhiambo, R. O. (2015). Multidimensional Analysis of the Determinants of Poverty Indicators in the Lake Victoria Basin(Kenya). IOSR Journal of Mathematics (IOSR-JM), 11 (3), 7387.

Oruc, N. (2015). Urban IDPs and Poverty: Analysis of the Effect of Mass Forced Displacement on Urban Poverty in Bosnia and Herzegovina. Croatian Economic Survey, 17 (1), 47-70.

Rashidghalam, M. (2017). Analysis of poverty and its determinants in Rwanda. Economic Transformation for Poverty Reduction in Africa, 104-120.

Rogan, M. (2016). Gender and multidimensional poverty in South Africa: Applying the Global Multidimensional Poverty Index (MPI). Social Indicators Research , 987-1006.

Sharma, T. (2014). Determinant of Poverty in Ethiopia. Ethiopian Journal of Economics, 114-130.

Shete, M. (2010). Magnitude and Determinants of Rural Poverty in Zeghe Peninsula, Ethiopia. Jornal of Poverty, 308-328.

Shu, D., \& Wenqing, H. (2017). A New Method for Logistic Model Assessment. International Journal of Statistics and Probability, 6 (6), 120-127.

Spaho, A. (2014). Determinants of Poverty in Albania. Journal of Educational and Social Research, 4 (2), $157-$ 164.

Spieker, M. (2017). Migrants' experiences and stories:A gender analysis of urban poverty among young ruralurban migrants in Addis Ababa. Utrecht University, Faculty of Geosciences.

Tacoli, C., McGranahan, G., \& Satterthwaite, D. (2015). World Migration Report 2015. Urbanisation, RuralUrban Migration and Urban Poverty. London: International Institute for Environment and Development.

Teshome, K. D., \& Sharma, M. K. (2014). Determinant of Poverty in Ethiopia. Ethiopian Journal of Economics, 23 (1), 114-132.

Teshome, K., \& Sharma, M. K. (2014). Determinant of Poverty in Ethiopia. Ethiopian Journal of Economics, 23 (1), 114-130.

Touray, M. (2016). Definitions and measures of poverty. Nairobi: Internatinal Development Initiatives.

Tsegaye, M., Lemma, Z., \& Belaineh, L. (2014). Analysis of Rural Poverty and Exit time: The case of Gozamn District of East Gojjam Zone, Ethiopia. Journal of Economics and Sustainable Development, 5 (27), 310322.

United Nations Development Programme (UNDP). (2015). Accelerating Inclusive Growth for Sustainable Human Development in Ethiopia: National Human Development Report 2014 Ethiopia. Addis Ababa, Ethiopia: United Nations Development Programme.

(2013). World Urbanization Prospects. New York: The 2013 Revision - Highlights, United Nations, Economic and Social Affairs.

Wooldridge, J. (2002). Econometric Analysis of Cross Sectional and Panel Data. The MIT Press.

World Bank, G. (2017). Who Escaped Poverty and Who Was Left Behind? A Non-Parametric Approach to Explore Welfare Dynamics Using Cross-Sections. Washington, DC.: Policy Research Working Paper. . (2015). Improved Livelihoods of Urban Poor. Addis Ababa: World Bank Group NEWS RELEASE . (2015). Ethiopian Urbanization review: Urban institutions for a middle income Ethiopia. Washington, DC: Ethiopian Urbanization review. 


\section{Correlation Matrices}

\section{APPENDICES}

- corr sexhh age eduction empstat jexperiance wrkhour rsidenc marst famysize dep $>$ rti asset income saving credit remitance usnp socirelatn powsour health $($ obs $=99$ )

\begin{tabular}{|c|c|c|c|c|c|c|c|}
\hline & sexhh & age & eduction & empstat & jexper e & wrkhour & rsidenc \\
\hline sexhh & 1.0000 & & & & & & \\
\hline age & 0.1517 & 1.0000 & & & & & \\
\hline eduction & 0.1669 & -0.1904 & 1.0000 & & & & \\
\hline empstat & 0.3077 & 0.0475 & 0.0615 & 1.0000 & & & \\
\hline jexperiance & 0.2378 & 0.0839 & 0.0590 & 0.1336 & 1.0000 & & \\
\hline wrkhour & 0.2211 & -0.0339 & 0.1984 & 0.3749 & 0.3479 & 1.0000 & \\
\hline rsidenc & 0.0938 & 0.2022 & -0.1312 & 0.1255 & 0.3304 & -0.0353 & 1.0000 \\
\hline marst & 0.2537 & 0.2021 & 0.0092 & 0.3195 & 0.3037 & 0.2118 & 0.1776 \\
\hline famysize & -0.3358 & -0.0619 & -0.1617 & -0.2052 & -0.1849 & -0.2481 & -0.1875 \\
\hline deprti & -0.2993 & -0.0202 & -0.1682 & -0.1536 & -0.1983 & -0.1246 & -0.1616 \\
\hline asset & 0.2340 & 0.0035 & 0.0646 & 0.1013 & 0.4823 & 0.2197 & 0.2726 \\
\hline income & 0.2845 & -0.1307 & 0.1583 & 0.1784 & 0.3742 & 0.2026 & 0.2593 \\
\hline saving & 0.4726 & 0.0993 & 0.0864 & 0.1070 & 0.2605 & 0.1364 & 0.1251 \\
\hline credit & 0.2232 & 0.1066 & 0.1172 & 0.1512 & 0.2786 & 0.2488 & 0.3497 \\
\hline remitance & 0.0549 & 0.0584 & 0.1242 & -0.1366 & 0.0126 & 0.0227 & 0.0412 \\
\hline usnp & -0.0676 & 0.2562 & -0.1577 & -0.1352 & -0.0333 & -0.1740 & 0.3121 \\
\hline socirelatn & 0.0234 & 0.0604 & -0.0356 & -0.0226 & 0.5224 & 0.2673 & 0.2642 \\
\hline powsour & 0.0954 & -0.0292 & 0.0017 & -0.0809 & 0.2864 & 0.2944 & 0.2986 \\
\hline \multirow[t]{2}{*}{ health } & 0.1908 & -0.2143 & 0.1869 & 0.2569 & 0.1338 & 0.2411 & -0.1173 \\
\hline & marst & famysize & deprti & asset & income & saving & credit \\
\hline marst & 1.0000 & & & & & & \\
\hline famysize & -0.3102 & 1.0000 & & & & & \\
\hline deprti & -0.2450 & 0.7680 & 1.0000 & & & & \\
\hline asset & 0.2034 & -0.3649 & -0.3518 & 1.0000 & & & \\
\hline income & 0.1681 & -0.3163 & -0.2741 & 0.5600 & 1.0000 & & \\
\hline saving & 0.2320 & -0.2860 & -0.2381 & 0.2041 & 0.3120 & 1.0000 & \\
\hline credit & 0.3105 & -0.3927 & -0.3250 & 0.3356 & 0.3117 & 0.3362 & 1.0000 \\
\hline remitance & 0.0722 & -0.3262 & -0.3155 & 0.2145 & 0.0529 & 0.3384 & 0.2988 \\
\hline usnp & -0.0949 & 0.0229 & 0.1224 & 0.0813 & -0.0638 & -0.1571 & 0.0138 \\
\hline socirelatn & 0.1116 & -0.1740 & -0.1592 & 0.4601 & 0.3284 & 0.1175 & 0.2841 \\
\hline powsour & 0.2736 & -0.2597 & -0.2233 & 0.3174 & 0.2467 & 0.2227 & 0.2876 \\
\hline \multirow[t]{2}{*}{ health } & 0.0983 & -0.0861 & -0.0868 & 0.0783 & 0.0684 & 0.1153 & -0.0814 \\
\hline & remita e & usnp & socire n & powsour & health & & \\
\hline remitance & 1.0000 & & & & & & \\
\hline usnp & 0.0164 & 1.0000 & & & & & \\
\hline socirelatn & 0.0573 & 0.0645 & 1.0000 & & & & \\
\hline powsour & 0.2858 & 0.1672 & 0.2645 & 1.0000 & & & \\
\hline health & 0.1048 & -0.0836 & -0.0210 & 0.0583 & 1.0000 & & \\
\hline
\end{tabular}




\title{
Binary logit estimation result
}

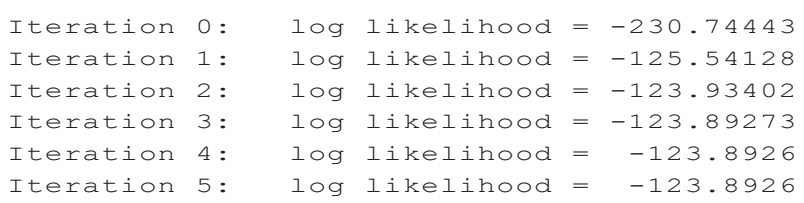

\begin{tabular}{|c|c|c|c|c|c|c|}
\hline sexhh & .0177409 & .0203978 & 0.87 & 0.385 & -.0223963 & .0578781 \\
\hline agesqu & .0000983 & .000036 & 2.73 & 0.007 & .0000276 & .0001691 \\
\hline education & -.0048379 & .0017825 & -2.71 & 0.007 & -.0083453 & -.0013304 \\
\hline empstat & .000332 & .0247393 & 0.01 & 0.989 & -.048348 & .0490121 \\
\hline wrkhour & -.0027441 & .0031008 & -0.88 & 0.377 & -.0088456 & .0033575 \\
\hline residence & .0003236 & .0009516 & 0.34 & 0.734 & -.0015489 & .002196 \\
\hline marst & -.0080608 & .0211731 & -0.38 & 0.704 & -.0497235 & .0336019 \\
\hline famysize & -.0101829 & .010586 & -0.96 & 0.337 & -.0310133 & .0106474 \\
\hline depratio & .037885 & .0114833 & 3.30 & 0.001 & .015289 & .060481 \\
\hline remitance & -.0834403 & .0215928 & -3.86 & 0.000 & -.1259289 & -.0409516 \\
\hline usnp & -.0029085 & .0184734 & -0.16 & 0.875 & -.0392589 & .033442 \\
\hline socirelatn & -.0155776 & .0207689 & -0.75 & 0.454 & -.056445 & .0252898 \\
\hline powsour & -.0078548 & .0216316 & -0.36 & 0.717 & -.0504196 & .0347101 \\
\hline health & .0309432 & .0256537 & 1.21 & 0.229 & -.0195361 & .0814224 \\
\hline _cons & 1.296316 & .1141512 & 11.36 & 0.000 & 1.071698 & 1.520934 \\
\hline
\end{tabular}

\section{Link tests of the model}

\author{
- linktest
}

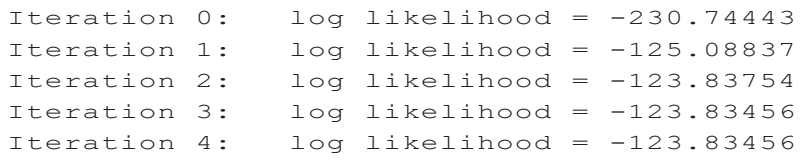

\begin{tabular}{|c|c|c|c|c|c|c|}
\hline poverty & Coef. & std. Err. & z & $P>|z|$ & Conf. & Interval] \\
\hline hat & .9926937 & .099043 & 10.02 & 0.000 & .7985729 & 1.186814 \\
\hline hatsq & .0201711 & .0594454 & 0.34 & 0.734 & -.0963397 & .136682 \\
\hline _cons & -.0614603 & .2450734 & -0.25 & 0.802 & -.5417953 & .4188748 \\
\hline
\end{tabular}


- estat class

Logistic model for poverty

\begin{tabular}{c|rr|r}
\cline { 2 - 3 } Classified & D & $\sim \mathrm{D}$ & Total \\
\hline+ & 130 & 17 & 147 \\
- & 33 & 153 & 186 \\
\hline Total & 163 & 170 & 333
\end{tabular}

Classified + if predicted Pr(D) $>=.5$

True $\mathrm{D}$ defined as poverty $!=0$

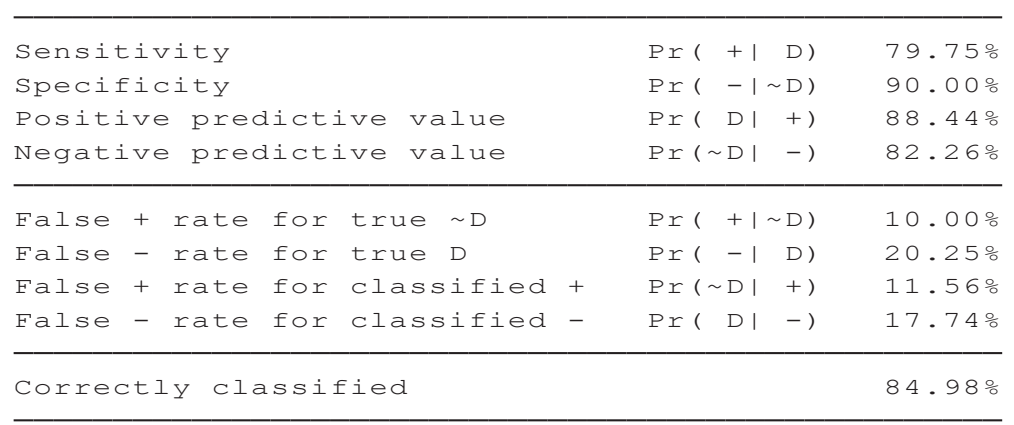

- 1 roc

Logistic model for poverty

number of observations $=333$

area under ROC curve $=0.9077$

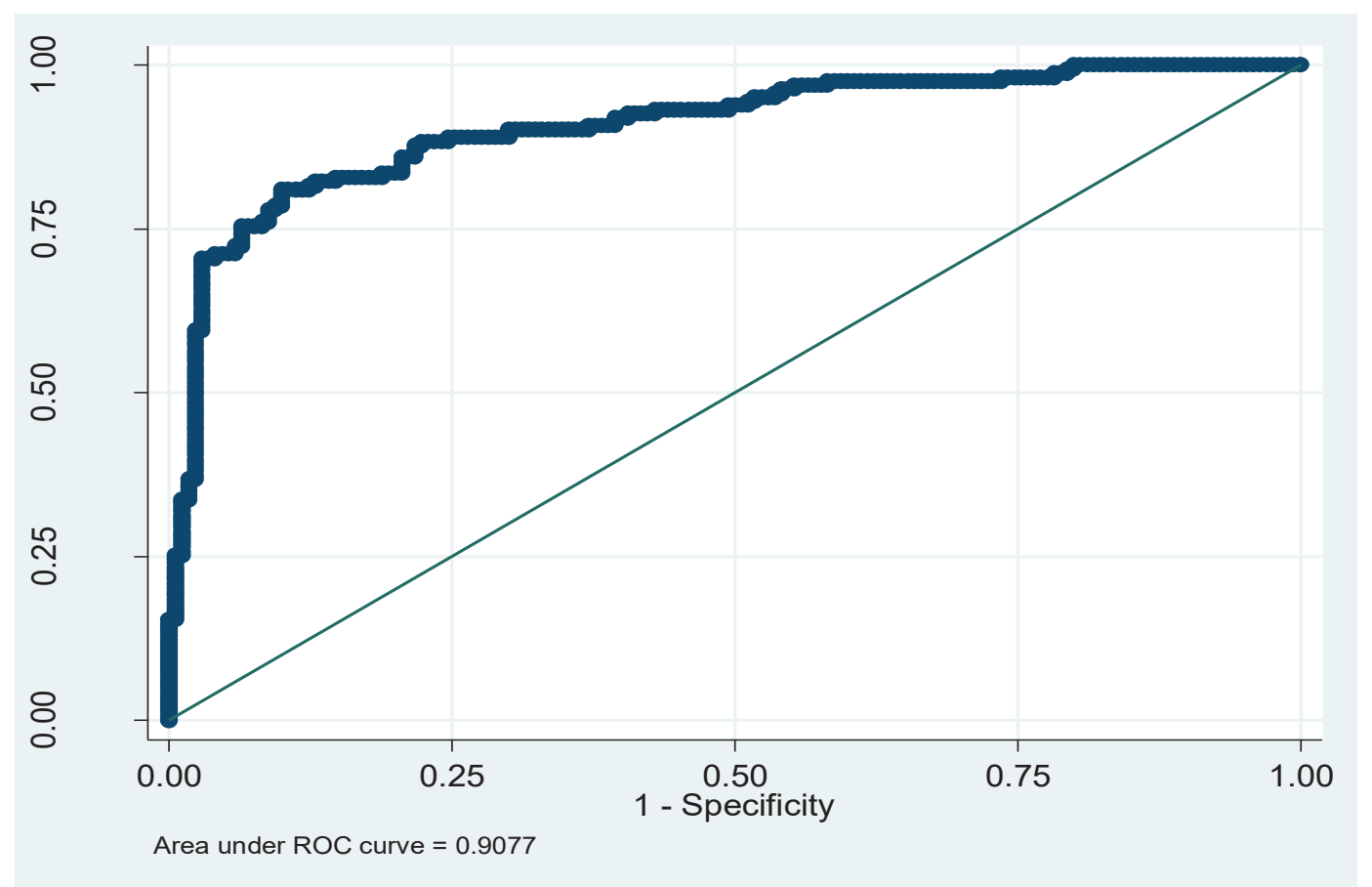




\section{ROC curves of the mode}

. lfit

Logistic model for poverty, goodness-of-fit test

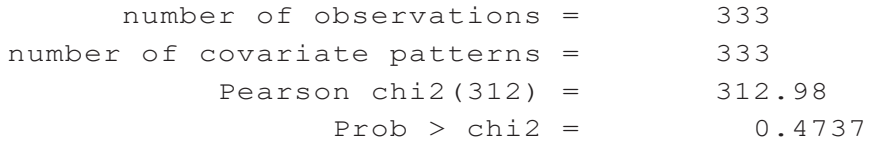

- lfit, group(10) table

Logistic model for poverty, goodness-of-fit test

(Table collapsed on quantiles of estimated probabilities)

\begin{tabular}{|c|c|r|r|r|r|r|}
\hline Group & Prob & Obs_1 & Exp_1 & Obs_0 & Exp_0 & Total \\
\hline 1 & 0.0789 & 0 & 2.0 & 34 & 32.0 & 34 \\
2 & 0.1124 & 4 & 3.3 & 29 & 29.7 & 33 \\
3 & 0.1484 & 7 & 4.3 & 26 & 28.7 & 33 \\
4 & 0.2195 & 5 & 6.1 & 29 & 27.9 & 34 \\
5 & 0.3275 & 12 & 9.2 & 21 & 23.8 & 33 \\
\hline 6 & 0.6804 & 13 & 16.4 & 20 & 16.6 & 33 \\
7 & 0.8892 & 27 & 28.2 & 7 & 5.8 & 34 \\
9 & 0.9312 & 33 & 30.2 & 0 & 2.8 & 33 \\
10 & 0.9554 & 30 & 31.1 & 3 & 1.9 & 33 \\
& 0.993 & 32 & 32.2 & 1 & 0.8 & 33 \\
\hline
\end{tabular}

$\begin{array}{rlc}\text { number of observations } & = & 333 \\ \text { number of groups } & = & 10 \\ \text { Hosmer-Lemeshow chi2(8) } & = & 11.07 \\ \text { Prob }>\operatorname{chi} 2 & = & 0.1979\end{array}$

